Seção III - Ensino de geografia: dimensões práticas para o cotidiano em sala de aula

\title{
A sala temática como um recurso didático nas aulas de geografia
}

\author{
Lincoln Santos dos Reis \\ Namara Santos Lopes \\ Tereza G. N. Torezani Fontes
}

\section{SciELO Books / SciELO Livros / SciELO Libros}

REIS, L.S., LOPES, N.S., and FONTES, T.G.N.T. A sala temática como um recurso didático nas aulas de geografia. In: TRINDADE, G.A., MOREIRA, G.L., ROCHA, L.B., RANGEL, M.C., and CHIAPETTI, R.J.N. Geografia e ensino: dimensões teóricas e práticas para a sala de aula [online]. Ilhéus: Editus, 2017, pp. 237-249. ISBN: 978-85-7455-526-3.

https://doi.org/10.7476/9788574555263.0015.

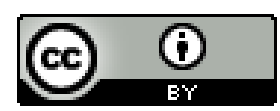

All the contents of this work, except where otherwise noted, is licensed under a Creative Commons Attribution 4.0 International license.

Todo o conteúdo deste trabalho, exceto quando houver ressalva, é publicado sob a licença $\underline{\text { Creative Commons }}$ Atribição 4.0.

Todo el contenido de esta obra, excepto donde se indique lo contrario, está bajo licencia de la licencia Creative Commons Reconocimento 4.0. 


\section{A SALA TEMÁTICA \\ COMO UM RECURSO \\ DIDÁTICO \\ NAS AULAS DE \\ GEOGRAFIA}

Lincoln Santos dos Reis

Namara Santos Lopes

Tereza G. N. Torezani Fontes

\section{INTRODUÇÃO}

A Geografia é uma área do conhecimento comprometida em tornar o mundo compreensível para os alunos, explicável e passível de transformações. Contudo, muitos professores que atuam na área passam por dificuldades e se frustram diariamente no desempenho de suas funções, especialmente no momento de estabelecer relação entre os conteúdos e o cotidiano dos alunos, a realidade concretamente vivenciada e experenciada por eles.

Dessa forma, de acordo com o Ministério da Educação e Cultura (MEC), a escola pública, em todos os níveis e modalidades da educação básica (educação infantil, ensino fundamental e médio), tem como função social formar o cidadão, isto é, construir conhecimentos, atitudes e valores que tornem o aluno solidário, crítico, ético e participativo nas decisões da sociedade.

A dificuldade dos professores de Geografia em estabelecer tais relações é uma das questões essenciais assinaladas por autores que discutem e debatem o ensino de Geografia (VESENTINI, 2004; CALLAI, 2002; OLIVEIRA, 1994; KAERCHER, 2002).

Diante dessa realidade, o impasse se revela: como favorecer o processo ensino-aprendizagem da disciplina Geografia e dirimir as dificuldades e frustrações experimentadas por professores dessa área? A utilização de recursos didáticos diferenciados e atraentes pode ser uma aliada na resolução de tal impasse. É nesse contexto que se insere a necessidade de implantação de uma sala temática de Geografia.

Assim, ao mesmo tempo em que a construção de conceitos geográficos vai acontecendo, criam-se condições dinâmicas de esclarecimento 
dos mesmos com a utilização da sala temática. As possibilidades de explorações temáticas e conceituais da Geografia a partir dos recursos em uma sala ambiente são muitas e a construção do conhecimento, em Geografia, pode ser facilitada pelo uso amplo e adequado dos recursos: globo terrestre, mapas, maquetes, jogos pedagógicos, revistas e outros materiais de consulta, aparelhos para medição de elementos climáticos, cartazes, mostruários de rochas e minerais, aparelhos para orientação, recursos audiovisuais (vídeo, slides, transparências), entre outros.

$\mathrm{O}$ aspecto e as estruturas físicas do ambiente exercem forte impacto sobre as ações dos alunos e, consequentemente, sobre sua aprendizagem. Nesse sentido, o presente artigo - resultado de uma monografia produzida no Curso de Especialização em Ensino de Geografia da UESC - teve como objetivo elaborar uma análise da sala temática como objeto de estudo do ensino de Geografia, estabelecendo um comparativo entre as aulas ministradas com e sem o uso desse tipo de sala.

Para alcançar os objetivos dessa pesquisa foram feitas revisões em bibliografias referentes ao assunto; simultaneamente foi aplicado um roteiro de observação sistemática em campo para a coleta de dados; finalmente, foi feito um registro narrativo de tudo o que foi constatado no período de observação.

\section{A IMPORTÂNCIA DA SALA TEMÁTICA PARA O PROCESSO ENSINO -APRENDIZAGEM}

Conforme observa Castrogiovanni (2000), a escola não tem se mostrado atraente frente ao mundo contemporâneo, pois não dá conta de explicar e contextualizar as novas leituras de vida. A escola parece ser homogênea, transparente e sem brilho. Já a vida fora da escola é cheia de mistérios, emoções, desejos e fantasias. Nesse sentido, é importante e urgente que se teorize a vida, para que o aluno possa compreendê-la e representá-la melhor. Como observou Kaercher (2002, p. 24): "Em minhas constatações a escola continua sendo um espaço de desconforto, desânimo $[\ldots] "$.

Vivemos, hoje, os desafios de uma revolução tecnológica que, paulatinamente, insere-se nos espaços escolares. No entanto, tais espaços, em muitas situações, não se apresentam de forma estruturada e organizada para tal feição. Percebe-se, cada vez mais, a necessidade de uma adequação efetiva dos ambientes escolares para que os mesmos possam se tornar interessantes instrumentos pedagógicos (CALLAI, 2002). 
Esta situação também é constatada por outra autora ao afirmar que:

O processo de ensino/aprendizagem realiza-se apoiado nas relações que se estabelecem entre professores, alunos e condições oferecidas ao processo pedagógico, constituindo um tripé que, se não for fortalecido em todas as suas bases, não oferecerá as condições necessárias à melhoria do processo (SPÓSITO, 2002, p. 308).

A maioria dos alunos não demonstra interesse pelos saberes das disciplinas, e na Geografia não é diferente. Conforme assinala Castrogiovanni (2000), muitos ainda acreditam que a Geografia é uma disciplina desinteressante, elemento de uma cultura que necessita da memória para reter nome de rios, regiões, países, altitudes, etc. Straforini (2004) reforça a afirmativa de que, na Geografia Escolar os conteúdos são tratados de forma superficial, apresentados de forma fragmentada e sem qualquer relação com a realidade e as demais disciplinas.

Para entender essa desmotivação, parte-se do pressuposto de que a causa desse problema pode estar no contexto das próprias aulas de Geografia onde, em muitos casos, o professor somente transmite conhecimentos. Da mesma maneira, o problema pode estar nas estratégias didáticas utilizadas pelos professores ou, mesmo, na falta destas, pois, nem todas as escolas possuem recursos didáticos, e nem todos os professores estão aptos ou dispostos a utilizar tais recursos, determinando, assim, desafios para o ensino de Geografia. Da mesma forma:

Todo professor que tentou inovar radicalmente, que mudou a sua prática educativa procurando realizar bons estudos do meio, selecionar textos críticos para leitura e discussão, abordar novos temas/problemas etc. conhece muito bem as enormes dificuldades que enfrentou (VESENTINI, 2004, p. 245).

Ou seja, professores planejam suas aulas, selecionam recursos didáticos necessários para a tarefa pedagógica, e a escola, por sua vez, não dispõe dos materiais indispensáveis para viabilizar a proposta didática planejada ou, se eles existem, são precários, obsoletos. Como discutem Pontuschka e Oliveira (2002, p. 189): "[...] o modo como o professor percebe a realidade pode se constituir em uma barreira, impedindo-o de ousar e experimentar alternativas pedagógicas".

Em muitos casos, a formação do professor é limitada, a utilização dos recursos é, para ele, um obstáculo, porque também não teve uma alfabetização geográfica e, assim, deparou-se com dificuldades na construção 
de noções e na elaboração de conceitos básicos que poderiam tornar mais concreto o ensino- aprendizagem.

Seja, então, por conta das dificuldades operacionais e materiais encontrados pelos docentes ou do próprio modo como o professor percebe a realidade e se posiciona frente a ela, o fato é que a prática de ensino nas aulas de Geografia merece tomar novos rumos.

Conforme afirma Xavier (2002, p. 65),

a prática do ensino da Geografia deve assegurar espaços de aprendizagem próprios, adequados à nova realidade do mundo e, assim, particularmente, à realidade da comunidade envolvida.

Busca-se uma prática pedagógica para ser alternativa ao ensino convencional, com utilização de metodologias e recursos os mais variados:

Diante desta questão existe por parte dos professores a utilização de diversas linguagens e recursos tecnológicos para se ensinar Geografia, tais como: cinema, fotografia, poesia, música, aulas temáticas, trabalhos de campo e, ainda, a utilização do espaço cibernético para interpretação e análise de ilustrações, charges, mapas, cartas, gráficos e tabelas, dentre outros (CAVALCANTI, 2005, p. 87).

Nesse sentido, é urgente repensarmos o estudo dos conteúdos geográficos, questionando fórmulas prontas, principalmente a dos livros didáticos e dos programas oficiais. O professor é fundamental nesse processo, afinal, um educador- geógrafo deve contribuir para a construção de uma escola cada vez mais voltada para a vida cidadã e de uma Geografia escolar cada vez mais útil e necessária (SILVA, 2004).

\section{O ENSinO de Geografia a PARTIR do uso da SALA TeMÁtica}

A sala temática articula um espaço lúdico com o cotidiano escolar do aluno, ampliando as possibilidades para que ele possa se expressar e se integrar ao ambiente que o cerca. Por meio das atividades lúdicas ele assimila valores, adquire conhecimento em diversas áreas do conhecimento, desenvolve o comportamento e aprimora as habilidades motoras. Por meio do lúdico o raciocínio é estimulado de forma prazerosa e a motivação para aprender é resgatada (SANTOS, 1999). 
Para Menezes e Santos (2002), sala ambiente é uma sala de aula na qual se dispõe de recursos didático-pedagógicos que atendam a um fim educacional específico. Os recursos didáticos utilizados tanto podem ser aqueles materiais já confeccionados como aqueles confeccionados na própria escola.

A existência de um espaço lúdico com recursos de ensino em sala de aula pode oferecer ao aluno possibilidades para que amplie sua leitura de mundo e sua ação crítica com base nas informações que tais recursos venham a oferecer.

Para Piletti (2006, p. 154), quando os usamos de maneira adequada, os recursos de ensino colaboram para:

- Motivar e despertar o interesse do aluno;

- Favorecer o desenvolvimento da capacidade de observação;

- Aproximar o aluno da realidade;

- Visualizar ou concretizar os conteúdos da aprendizagem;

- Oferecer informações e dados;

- Permitir a fixação da aprendizagem;

- Ilustrar noções mais abstratas;

- Desenvolver a experimentação concreta.

Em qualquer especialidade, utilizar-se de recursos didáticos para facilitar a aprendizagem é de grande importância, entretanto, a utilização destes recursos nas aulas de Geografia é mais significativa ainda, na medida em que servem de mediadores entre os conteúdos e o aluno, além de colocá-lo em contato maior com a materialidade.

Nesse sentido, conforme assinala Oliveira (2009, p. 5):

A adoção do uso dos recursos didáticos em uma sala temática de Geografia contribui para uma maior compreensão da sociedade, como o processo de ocupação dos espaços naturais, baseado nas relações do homem com o ambiente, em seus desdobramentos políticos, sociais, culturais e econômi$\cos$ - função fundamental do ensino de Geografia.

Cioccari (2012) assinala que uma sala-ambiente é mais do que um espaço diferenciado, é uma concepção de ensino que se distingue da tradicional, pois neste ambiente o aluno pode vivenciar, experimentar e praticar 
a Geografia, o que contribui para a sua formação temporal e espacial, e o insere de forma mais harmoniosa neste mundo em transformação.

Sendo assim, a implantação de uma sala temática é uma construção coletiva de conhecimento, na qual os recursos pedagógicos disponíveis podem dinamizar os trabalhos e enriquecer as atividades de ensino-aprendizagem da ciência geográfica, tornando esse processo mais prazeroso e eficaz. Além disso, é um espaço propício para estimular a construção e compreensão de conceitos, procedimentos e habilidades da ciência geográfica, ao mesmo tempo em que cria atitudes positivas em relação à mesma.

A observação e análise do espaço são fundamentais para que o aluno entenda os fenômenos geográficos e, na sala temática, essas tarefas se tornam mais relevantes a partir da utilização de alguns recursos (QUADRO 1).

\section{QUADRO 1 - Exemplos de materiais para sala temática de Geografia}

\begin{tabular}{|l|l|}
\hline Item & Descrição \\
\hline o1 & Globo terrestre. \\
\hline o2 & CDs E DVDs de documentários, filmes, músicas. \\
\hline 03 & Atlas, livros, revistas, jornais, cordéis. \\
\hline 04 & Mapas temáticos, cartas topográficas, plantas de municípios ou bairros. \\
\hline 05 & Maquetes variadas, painéis. \\
\hline 06 & Bingos geográficos. \\
\hline 07 & Jogos pedagógicos da área. \\
\hline 08 & Aparelhos para medição de elementos climáticos: termômetros, pluviômetros. \\
\hline o9 & Fotografias aéreas, gravuras, cartões postais, imagens de satélites. \\
\hline 10 & Mostruários de rochas e minerais. \\
\hline 11 & Aparelhos para orientação: bússolas, GPS. \\
\hline 12 & Recursos audiovisuais: aparelho de DVD, projetor de slides. \\
\hline
\end{tabular}

Fonte: Dados da pesquisa.

É interessante, também, disponibilizar matéria-prima para a confecção de outros materiais didáticos, como é o caso de: tinta, lápis de cor, giz de cera, massa de modelar, cartolina e materiais recicláveis como garrafas pets, cola, tesoura, entre outros.

De posse desses recursos materiais, aliado a um mobiliário que os exponha, a sala temática está pronta e propícia que o professor possa trabalhar os conteúdos articulados a um método ou a uma técnica que facilitará a compreensão do aluno, provocando uma situação de aprendizagem.

A FIGURA 1 demonstra a construção de uma sala temática, aonde o espaço vai ganhando forma e identidade geográficas, propiciando um estímulo a mais para a assimilação dos conteúdos da disciplina. 
FIGURA 1 - Sala temática de Geografia
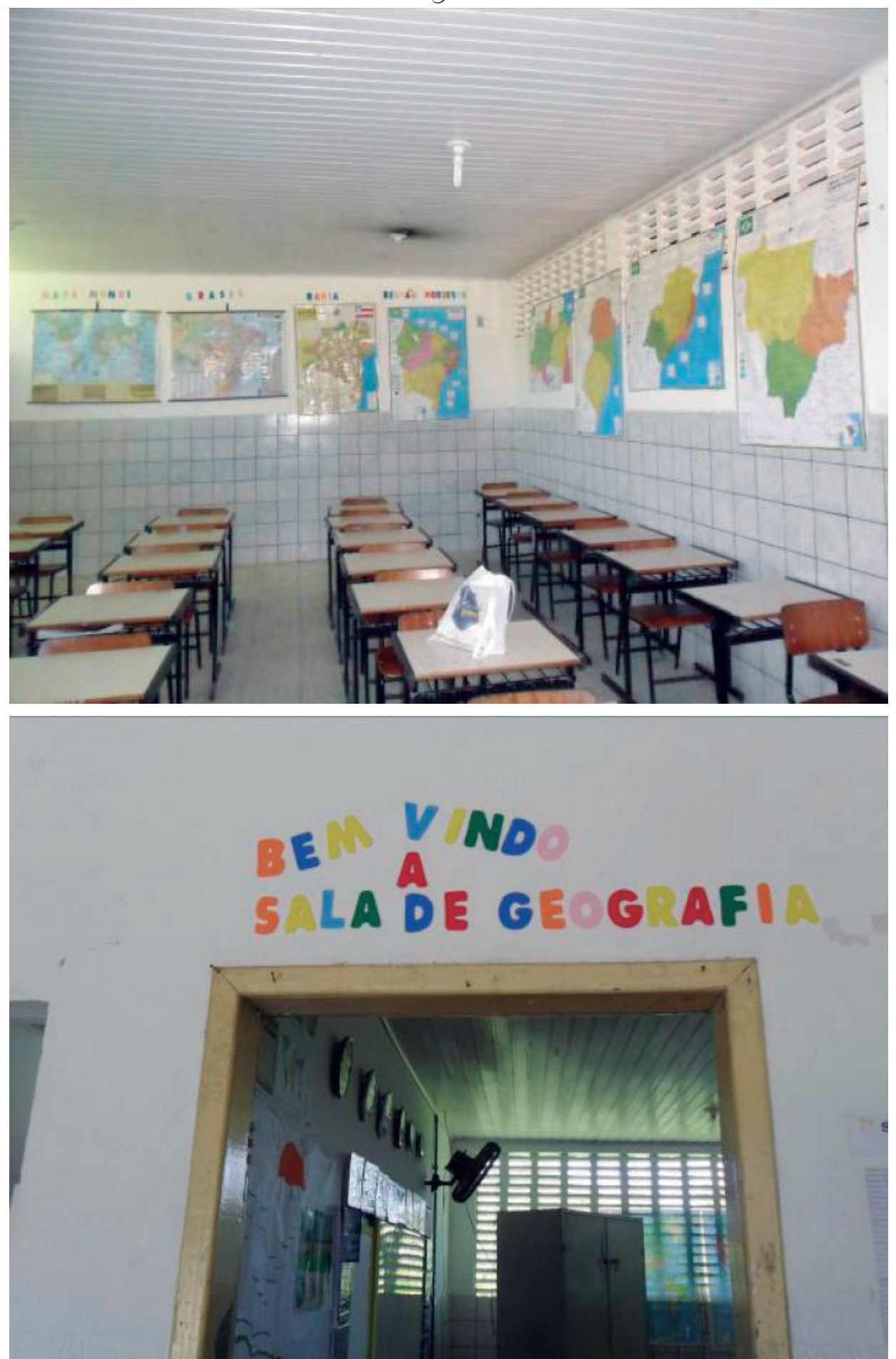

Fonte: Namara Santos Lopes, 2013. 
Enfim, a estratégia é mobilizar a curiosidade e o conhecimento que o aluno está construindo e, com base nisso, conduzir atividades em que vai localizar, mapear, comparar e analisar criticamente os fenômenos discutidos, ou seja, a proposta dessa alternativa pedagógica é facilitar o processo de ensino-aprendizagem, articulando teoria e prática (CIOCCARI, 2012).

\section{Comparativo ENTRE aS aUlas ministradas Na SALA CONVENCIO- NAL E NA SALA TEMÁTICA}

$\mathrm{Na}$ tentativa de obter um comparativo entre as aulas ministradas na sala convencional e na sala temática foi realizada uma observação com 30 alunos do $8^{\circ}$ ano da Escola Nucleada da rede municipal de ensino, de Ilhéus-BA. O roteiro da observação foi dirigido com a finalidade de verificar a interação dos alunos durante cinco aulas ministradas na sala convencional e cinco aulas na sala temática. Os assuntos trabalhados nas aulas foram: orientação, localização e fusos horários. O plano de aula foi levado a efeito, entretanto, com algumas alterações, já que as aulas na sala temática tiveram o auxílio dos equipamentos que lá se encontravam (FIGURA 2).

FIGURA 2 - Comparativo entre as aulas ministradas na sala temática de Geografia e na sala convenciona

Comparativo entre as aulas ministradas na sala temática e na sala convencional

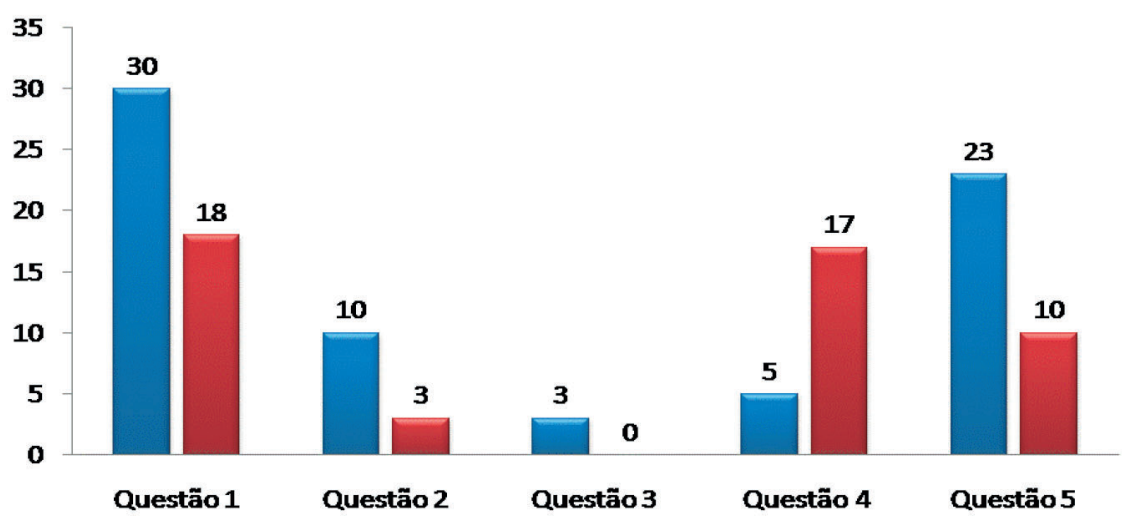

Questão 1- $O$ aluno presta atenção durante a explanação da aula? Questão 2- $O$ aluno Responde aos questionamentos da professora? Questäo 3-O aluno faz questionamentos? Questão 4- $O$ aluno pede orientação da atividade proposta na aula? Questāo 5-O aluno realiza a atividade proposta com êxito?

Fonte: Namara Santos Lopes, 2013.

Legenda: Sala Temática; Sala convencional. 
Assim, durante os trinta minutos de explanação da aula na sala temática, conseguiu-se obter a atenção máxima dos alunos, trinta ao todo, ou seja, todos os alunos estiveram bastante atentos, mostrando-se muito curiosos com aquela formatação de aula, onde vários recursos eram utilizados, enquanto na sala convencional a mesma aula ministrada com os recursos utilizados habitualmente, como o quadro branco e canetas piloto, obteve apenas a atenção integral de dezoito alunos.

A professora fez três questionamentos referentes à temática da aula. Durante a aula ministrada na sala convencional, apenas três alunos se prontificaram a responder, enquanto que na sala temática dez alunos tentaram responder utilizando os recursos ao seu alcance.

A professora deixou espaço para que os alunos fizessem também questionamentos referentes ao que foi explanado na aula. Na sala convencional nenhum aluno se pronunciou, enquanto na sala temática três alunos se arriscaram a formular perguntas.

Foram realizadas três atividades durante as aulas. Na sala convencional dezessete alunos pediram orientações à professora, enquanto na sala temática apenas cinco alunos pediram orientação. Esse fato revela que, na sala temática os alunos tiveram maior autonomia, enquanto na sala convencional as atividades indicaram ser mais complicadas.

Ao realizar a correção das atividades para verificar se os alunos as executaram com êxito, na sala temática dezenove tiveram sucesso; já, na sala convencional só dez tiveram um bom resultado. Isto nos leva a concluir que a aula na sala temática oferece melhores condições de aprendizagem.

\section{Conclusão}

Os resultados deste trabalho demonstraram que, ao levar para a sala de aula materiais e propostas de trabalho centradas na ludicidade, despertou-se a curiosidade dos alunos, até mesmo daqueles que, por vezes, não se interessavam pelo conteúdo. Quando observaram a utilização de um recurso didático queriam saber do que tratavam os assuntos e procuravam participar. Assim, presume-se que houve maior integração entre os alunos e os conteúdos, de maneira prazerosa e altamente proveitosa.

Os alunos foram convidados, também, a confeccionar os próprios recursos didáticos, e ao desempenharem esta atividade, demonstraram envolvimento e satisfação, participando ativamente na aula, criando e manipulando materiais. Habitualmente é o professor quem manipula os materiais e, somente em seguida, os apresenta aos alunos. 
No que se refere aos recursos cartográficos, como estes estavam sempre ao alcance dos alunos, permitiram um aguçamento de sua curiosidade. À medida que eram citados fatos ocorridos em localidades desconhecidas, os alunos imediatamente procuravam os lugares nos mapas ou no globo, ou seja, estas ferramentas trouxeram, para o campo de visão daqueles usuários, uma parte da realidade distante, e, assim, incentivaram o seu processo de construção do conhecimento autônomo, ao mesmo tempo em que permitiram maior interação dos mesmos com a Geografia enquanto ciência espacial.

Os materiais da sala temática de Geografia se mostraram úteis, também, para outras disciplinas. Isso foi constatado durante o conselho de classe, no qual o professor de História relatou ter tido bom proveito dos materiais.

Com a realização deste projeto houve evidências de que a experiência da utilização de sala temática para as aulas de Geografia serviu como um ambiente que facilitou o processo ensino-aprendizagem tanto para o aluno como para o professor, na medida em que permitiu reorganização, reestruturação e ressignificação do trabalho pedagógico.

Sabe-se que a Geografia Escolar influencia sobremaneira a formação do aluno, do homem-cidadão, por conseguinte, a importância dessa metodologia de trabalho é indiscutível. É necessário que os profissionais da área se deem conta da sua responsabilidade: a de desempenhar um trabalho pedagógico atraente, desafiante e inovador, que contribua para um conhecimento significativo. A experiência relatada nesse artigo revelou apenas algumas das possibilidades abertas para se alcançar essa meta, através do uso da sala temática nas aulas de Geografia, na educação básica. 


\section{REFERÊNCIAS}

BRASIL. Secretaria de Educação Fundamental. Parâmetros Curriculares Nacionais: Geografia. Secretaria de Educação Fundamental. Brasília, DF: MEC: SEF, 1998.

CALLAI, H. C. Projetos interdisciplinares e a formação do professor em serviço. In: PONTUSCHKA, Nídia; OLIVEIRA, Ariovaldo U. Geografia em perspectiva. São Paulo: Contexto, 2002. p.

CASTROGIOVANNI, A. C. (org.). Ensino de Geografia: práticas e textualizações no cotidiano. Porto Alegre: Mediação, 2000.

CAVALCANTI, L. de S. Geografia e práticas de ensino. Goiânia: Alternativa, 2005.

CIOCCARI, C. C. Sala ambiente de Geografia em escola pública. 2012. Disponível em: <http://unicruz.edu.br/mercosul/pagina/anais/2012/Educacaoedesenvolvimentohumano/ artigo/salaambientedegeografiaemescolapublica.pdf $>$. Acesso em: 20 mar. 2012.

FIORENTINI, D.; LORENZATO, S. Investigação em educação matemática: percursos teóricos e metodológicos. Campinas: Autores Associados, 2006.

KAERCHER, N. A. O gato comeu a Geografia Crítica? Alguns obstáculos a superar no ensino-aprendizagem de Geografia. In: PONTUSCHKA, N. N.; OLIVEIRA, A. O. (Orgs.). Geografia em perspectiva. São Paulo: Contexto, 2002. p. 221-231.

LIMA, M. G. A pesquisa acadêmica e a sua contribuição para a formação do professor. In: PONTUSCHKA, N. M.; OLIVEIRA, A. O. (org.). Geografia em perspectiva. São Paulo: Contexto. 2002. 
LIMA, M. W. S. Arquitetura e educação. São Paulo: Studio Nobel, 1995.

MENEZES, E. T.; SANTOS, T. H. dos. Sala ambiente.

Dicionário Interativo da Educação Brasileira. Educa Brasil.

[S.l., [21-?]]. Disponível em: <http://www.educabrasil.com.br/ eb/dic/dicionário.asp? Id=62>. Acesso em: 29 abr. 2012.

OLIVEIRA, M. L. T. de. Ensino de Geografia na contemporaneidade: o uso de recursos didáticos na sua abordagem. [S.l.], 2009. Disponível em: <http://www.agb.org.br/ XENPEG/artigos/GT/GT5/tc5\%20(51).pdf $>$. Acesso em: 29 abr. 2012.

OLIVEIRA, A. U. Situação e tendências da Geografia. In: (org.). Para onde vai o ensino de Geografia? 4. ed. São Paulo: Contexto, 1994.

PONTUSCHKA, N. N.; OLIVEIRA, A. U. (org.). Geografia em perspectiva: ensino e pesquisa. São Paulo: Contexto, 2002. SANTOS, M. P. dos. Brinquedoteca: o lúdico em diferentes contextos. 4. ed. São Paulo: Vozes, 1999.

SILVA, O. A. da. Geografia: metodologias e técnicas de ensino. Feira de Santana: Editora da Universidade Estadual de Feira de Santana, 2004.

STRAFORINI, R. Ensinar Geografia: o desafio da totalidade -mundo nas séries iniciais. São Paulo: Annablume, 2004.

SPÓSITO, M. E. As diferentes propostas curriculares e o livro didático. In: PONTUSCHKA, N. N.; OLIVEIRA, A. U. (org.) Geografia em perspectiva: ensino e pesquisa. São Paulo:

Contexto, 2002.

VESENTINI, J. W. Geografia Crítica e ensino. In: OLIVEIRA, A. U. (org.). Para onde vai o ensino de Geografia? 4. ed. São Paulo: Contexto, 1994. 
VESENTINI, J. W. O ensino de Geografia no século XXI. Campinas: Papirus, 2004. (Coleção Papirus Educação).

XAVIER, H. A incorporação da dimensão do turismo do ensino da Geografia. In: PONTUSCHKA, N. N.; OLIVEIRA, A.

U. (org.). Geografia em perspectiva: ensino e pesquisa. São Paulo: Contexto, 2002. 